\title{
Renal Functional Reserve Is Related to the Nondipping Phenotype and to the Exercise Heart Rate Response in Patients with Essential Hypertension and Preserved Renal Function
}

\author{
Katerina Damianaki ${ }^{a}$ Michel Burnier ${ }^{b} \quad$ Kyriakos Dimitriadis $^{c}$ \\ Costas Tsioufis ${ }^{c}$ Dimitrios Petras ${ }^{a}$ \\ a Service of Nephrology, University Hospital of Athens, Hippokration Hospital, Athens, \\ Greece; bService of Nephrology and Hypertension, University Hospital of Lausanne, \\ Lausanne, Switzerland; ${ }^{C}$ First Cardiology Clinic, National and Kapodistrian University of \\ Athens, Medical School, Hippokration Hospital, Athens, Greece
}

\section{Keywords}

Renal functional reserve $\cdot$ Blood pressure $\cdot$ Circadian pattern $\cdot$ Heart rate response $\cdot$ Exercise test

\begin{abstract}
Background: Renal functional reserve (RFR), defined as the difference between stress and resting glomerular filtration rate (GFR), may constitute a diagnostic tool to identify patients at higher risk of developing acute kidney injury or chronic kidney disease. Blunted RFR has been demonstrated in early stages of hypertension and has been attributed to impaired vascular reactivity due to an overactive sympathetic nervous system (SNS). Objective: The purpose of this study was to investigate whether RFR correlates with other phenotypes expressing overactivity of the SNS in patients with essential hypertension and preserved renal function. Methods: Thirty-six patients with untreated essential hypertension and a GFR $>60 \mathrm{~mL} / \mathrm{min} / 1.73 \mathrm{~m}^{2}$ were enrolled. The following parameters were measured: RFR, 24-h ambulatory blood pressure (BP) profile, a treadmill stress test, and an echocardiographic examination. Urine and venous samples were obtained at specific time points for the determination of clinical parameters, and both resting and stress GFR were calculated by using endogenous creatinine clearance for the measurement of RFR after an acute oral protein load $(1 \mathrm{~g} / \mathrm{kg})$. $\boldsymbol{R e}$ sults: Twenty-one patients had a RFR $<30 \mathrm{~mL} / \mathrm{min} / 1.73 \mathrm{~m}^{2}$ and 15 had a RFR above this cutoff. A nondipping pattern of 24-h BP was significantly more frequent in patients with low RFR (57.1 vs. $25.0 \%, p<0.05$ for systolic BP and 52.3 vs. $10.0 \%, p<0.02$ for diastolic BP). Moreover, pa-
\end{abstract}




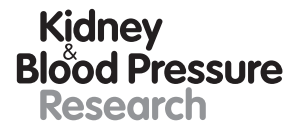

Research

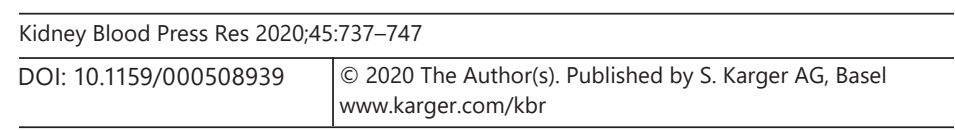

Damianaki et al.: Renal Functional Reserve, Exercise Heart Rate, and Circadian Blood Pressure

tients with lower RFR values showed a blunted heart rate (HR) response to exercise during treadmill test $(r=0.439, p<0.05)$. None of the echocardiographic parameters differed between the two groups of patients. Conclusions: In hypertensive patients with preserved GFR, reduced RFR is related to nondipping BP phenotype as well as to attenuated exercise HR response. Overactivity of the SNS may be a common pathway. Since loss of RFR may represent a risk factor for acute or chronic kidney injury, hypertensive patients with blunted RFR might need a more careful renal follow-up.

(C) 2020 The Author(s)

Published by S. Karger AG, Basel

\section{Introduction}

Static measurement or estimation of glomerular filtration rate (GFR) based on serum creatinine ( $\mathrm{SCr}$ ) does not necessarily provide accurate information regarding early nephron loss and renal functional mass because of renal adaptive processes [1]. Thus, it is well recognized that patients can lose up to $50 \%$ of their GFR with almost no change in SCr. Therefore, there is a definite need for a more sensitive and prognostic functional marker of renal function loss when it is still clinically silent. In this context, the ability to determine "kidney reserve" boosted the interest of the nephrology community in the measurement of renal functional reserve (RFR) [2,3]. RFR describes the capacity of the kidney to augment its level of function under certain stimuli. Practically, it can be estimated as the difference between stress and resting GFR after intravenous amino acid infusion or after short-term oral protein loading, the latter being a less complicated and easier method to apply [4, 5]. The two assessment techniques may provide slightly different results because the intravenous approach shunts the gastrointestinal tract and several studies have shown that food intake affects renal function, and in particular GFR, via several vasoactive gut hormones and peptides, which have now been recognized as important mediators of the gut-renal axis [6]. Other proposed mechanisms for the GFR increase after an acute protein load include the release of nitric oxide and prostaglandins, resulting in vasodilation as well as increase in renal blood flow and GFR in the presence of a constant filtration fraction. A reduction in RFR has been demonstrated in several patient groups, mainly in those with chronic kidney disease and/or type 2 diabetes [3].

Previous studies have also reported reduced RFR values in patients with essential hypertension [7-9]. Thus, low RFR values have been measured in patients with essential hypertension as compared to healthy control subjects as well as in offspring of patients with essential hypertension [8]. However, the precise mechanisms of these early reductions in RFR in hypertension remain poorly understood. They have been interpreted as indirect signs of altered systemic and renal hemodynamic regulation linked to impaired vascular reactivity commonly observed in patients with essential hypertension [10]. In this respect, overactivity of the sympathetic nervous system (SNS), observed even in very early stages of hypertension, may play an important role [11]. Indeed, overactivity of the SNS has been associated with increases in resting heart rate (HR), cardiac output, and renal vascular resistance in hypertensive patients [12]. It has also been associated with changes in the 24-h blood pressure (BP) profile as observed in patients with the nondipping phenotype [13].

In the present study we aimed to investigate the relations between RFR and several phenotypes influenced by the SNS and reflecting a preserved vascular reactivity such as the 24-h ambulatory BP phenotype, the hemodynamic response to a treadmill stress test, and cardiac parameters as measured by echocardiography in patients with essential hypertension and preserved renal function. 


\section{Kidney \\ Blood Pressure \\ Research}

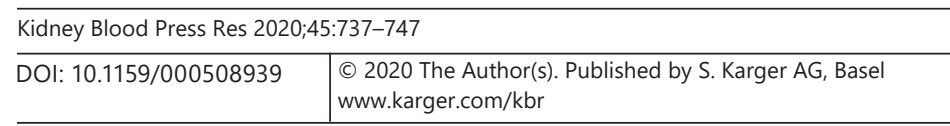

Damianaki et al.: Renal Functional Reserve, Exercise Heart Rate, and Circadian Blood Pressure

\section{Subjects and Methods}

\section{Study Participants}

The study population consisted of patients with untreated essential hypertension who were referred or self-referred to the outpatient hypertension unit with an estimated GFR (eGFR) $>60 \mathrm{~mL} / \mathrm{min} / 1.73 \mathrm{~m}^{2}$. The Modification of Diet in Renal Disease equation was used to calculate eGFR [14]. The diagnosis of hypertension was based on three outpatient measurements of BP $>140 / 90 \mathrm{~mm}$ Hg using a validated BP measurement device and confirmed by daytime ambulatory BP $>135 / 85 \mathrm{~mm} \mathrm{Hg}$ (see below). All subjects underwent the usual clinical and laboratory workup in order to rule out secondary forms of hypertension [15]. Exclusion criteria were presence of diabetes, presence of cardiovascular disease, pregnancy, body mass index $>35$, proteinuria $>0.3 \mathrm{~g} / 24 \mathrm{~h}$, history of malabsorption/chronic inflammatory bowel disease/pancreatic insufficiency, kidney stones/cysts/atrophy on renal ultrasound, and renal artery stenosis. Inclusion criteria were age $>18$ years and the ability to understand the study protocol and to sign informed consent. The study protocol included laboratory measurements, 24-h ambulatory BP monitoring, echocardiographic examination, anthropometric determinations, treadmill stress test, and measurement of RFR in all participants.

\section{RFR Estimation}

Subjects were studied in the supine position, having fasted for $8 \mathrm{~h}$ and having abstained from smoking, alcohol, and caffeinated beverages in the $12 \mathrm{~h}$ before the study. RFR was assessed by using a previously described kidney stress test [16]. Briefly, the baseline hydration status was recorded for all subjects using bioimpedance analysis (Body Composition Monitor, Fresenius) and then hydration was obtained with $20 \mathrm{~mL} / \mathrm{kg}$ of water orally while oral water was given in volumes equaling the urinary volumes of specific timings to maintain hydration until the end. Resting GFR was calculated by using endogenous creatinine clearance $(\mathrm{CrCl})$ and was corrected for body surface area with the use of the Dubois method [17]. Urine collection was performed by supervised voiding and confirmed for completeness by bladder scanning. Based on previous studies showing that peak GFR rarely occurs beyond $3 \mathrm{~h}$ of a protein meal, the test was terminated after that time [18-20]. To mobilize the RFR, an oral protein load of $1 \mathrm{~g} / \mathrm{kg}$ at $120 \mathrm{~min}$ was given as cooked meat prepared at the General Hospital of Athens "Hippokration." Stress GFR was then calculated as mentioned above (see online suppl. material; for all online suppl. material, see www.karger.com/doi/10.1159/000508939). Hydration status was also measured at the end of the test. RFR was defined as the difference between stress and resting GFR. Normal RFR was defined as $\geq 30 \mathrm{~mL} / \mathrm{min} / 1.73 \mathrm{~m}^{2}$ based on previous studies $[16,18,21]$.

\section{Determination of Laboratory Parameters}

Venous blood sampling was performed for estimation of $\mathrm{SCr}$ at times 30, 90, 210, and $270 \mathrm{~min}$. Urine samples for measuring urinary creatinine (UCr) were obtained at times 60, 120,240 , and $300 \mathrm{~min}$. At time $120 \mathrm{~min}$ the protein load was given to the subjects as cooked red meat for ingestion (online suppl. Fig. 1). Resting and stressed GFR were calculated by using the corrected $\mathrm{CrCl}$ formula as shown below: $\mathrm{CrCl}=\mathrm{UCr} / \mathrm{SCr} \times$ urinary volume $/$ time $\times$ 1.73 / body surface area. Fasting glucose levels, lipid profile including low-density cholesterol, triglycerides, and uric acid were also determined at time $30 \mathrm{~min}$.

\section{Office and Ambulatory BP Measurements}

Office BP measurement was recorded on three different visits scheduled 1 week apart in our outpatient clinic, according to guidelines, using an automatic oscillometric device (Dinamap XL; Johnson \& Johnson Inc., Raritan, NJ, USA). More specifically, office BP was defined as the average BP value derived from the three different visits [15]. Ambulatory BP 


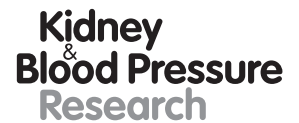

Research

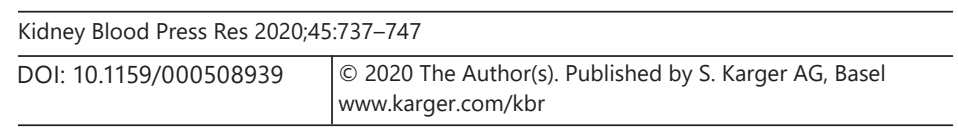

Damianaki et al.: Renal Functional Reserve, Exercise Heart Rate, and Circadian Blood Pressure

was recorded over a working day (Monday through Friday) using the automatic Spacelabs units 90207 (Redmond, WA, USA). The procedure has been described previously [22]. In brief, the cuff was fixed to the nondominant arm and the device was set to obtain automatic HR and BP readings at 15-min intervals during daytime and at 30-min intervals during nighttime. In keeping with current practice, daytime and nighttime were defined using short fixed-clock time intervals, which ranged from 10.00 a.m. to 8.00 p.m. and from midnight to 6.00 a.m., respectively. Twenty-four-hour systolic BP (SBP) and diastolic BP (DBP) values were the mean of the overall 24 -h recordings after editing and removing artifacts. Nondipping was defined as a reduction in nighttime BP of $<10 \%$.

\section{Treadmill Stress Test}

Study participants performed symptom-limited exercise testing according to the multistage Bruce protocol on a Quinton 5000 treadmill system (Quinton Instruments, Seattle, WA, USA) [23]. The highest SBP value achieved during the exercise stress test was the peak exercise SBP and accordingly a hypertensive response to exercise was defined as a peak exercise SBP $\geq 210 \mathrm{~mm} \mathrm{Hg}$, in line with the Framingham criteria, while reasons for exercise test termination have been previously described [24].

\section{Echocardiographic Examination}

The echocardiographic studies were performed by an experienced senior cardiologist who was blind to the clinical status of the examined subject, using a General Electric medical Systems Vivid 3 ultrasound imager equipped with a 2.25-e5-MHz transducer, according to the recommendations of the American Society of Echocardiography [25]. The echocardiographic parameters measured were diastolic function indices (transmitral flow E and A), left ventricular end-diastolic and systolic diameters, interventricular septum and posterior wall thickness, left atrial diameter, as well as left ventricular ejection fraction.

\section{Statistical Analysis}

The analysis was done dividing patients according to the level of RFR, i.e., $\geq 30$ or $<30 \mathrm{~mL} /$ $\mathrm{min} / 1.73 \mathrm{~m}^{2}$. SPSS statistical package (IBM SPSS Statistics version 23) was used for all statistical analyses. Significant differences between the study groups were determined using the Student independent-samples $t$ test or the $\chi^{2}$ test where appropriate. Correlation analyses were performed using the Pearson correlation coefficient. Descriptive statistics were arithmetic means \pm standard deviations. Statistical significance was set equal to $5 \%$.

\section{Results}

\section{Study Population and Characteristics}

Thirty-six patients with untreated essential hypertension were enrolled in this study. They were divided into two groups based on their response to the acute protein load defining their RFR. Fifteen patients had a normal RFR $\left(\geq 30 \mathrm{~mL} / \mathrm{min} / 1.73 \mathrm{~m}^{2}\right)$ and 21 had a reduced RFR. As shown in Table 1, the two groups did not differ in terms of age, body mass index, sex, family history and duration of hypertension, smoking status, office BP and HR, waist-hip ratio, baseline eGFR, glucose levels, and lipid profile.

\section{4-Hour Ambulatory BP Monitoring Data}

As shown in Table 2, there were no significant differences in 24-h ambulatory SBP and DBP and 24-h ambulatory HR between hypertensive patients with preserved or reduced RFR. However, the proportion of nondippers (for both SBP and DBP) is expected to be significantly 


\section{Research}

Damianaki et al.: Renal Functional Reserve, Exercise Heart Rate, and Circadian Blood Pressure

Table 1. Baseline characteristics of hypertensive patients with RFR $<30$ and $\geq 30 \mathrm{~mL} / \mathrm{min} / 1.73 \mathrm{~m}^{2}$

\begin{tabular}{lccc}
\hline Parameter & $\begin{array}{l}\mathrm{RFR}<30 \mathrm{~mL} / \mathrm{min} / \\
1.73 \mathrm{~m}^{2}(n=21)\end{array}$ & $\begin{array}{c}\mathrm{RFR} \geq 30 \mathrm{~mL} / \mathrm{min} / \\
1.73 \mathrm{~m}^{2}(n=15)\end{array}$ & $p$ value \\
\hline Age, years & $52.88 \pm 11.53$ & $50.25 \pm 14.88$ & 0.56 \\
Males, \% & 71.4 & 53.3 & 0.27 \\
Body mass index & $27.07 \pm 2.88$ & $29.90 \pm 6.24$ & 0.07 \\
Smoking, \% & 28.6 & 40 & 0.47 \\
Waist-hip ratio & $0.91 \pm 0.07$ & $0.92 \pm 0.10$ & 0.87 \\
Positive family history, \% & 71.4 & 73.3 & 0.90 \\
Duration of AH $>10$ years, \% & 4.7 & 13.3 & 0.36 \\
Office SBP, mm Hg & $138.29 \pm 10.96$ & $143.40 \pm 15.80$ & 0.26 \\
Office DBP, mm Hg & $84.54 \pm 10.35$ & $92.42 \pm 12.92$ & 0.06 \\
Office HR, bpm & $77.46 \pm 8.57$ & $79.00 \pm 12.86$ & 0.67 \\
Glucose, mg/dL & $87.63 \pm 9.60$ & $88.00 \pm 17.74$ & 0.93 \\
Urea, mg/dL & $31.88 \pm 5.35$ & $33.25 \pm 10.29$ & 0.67 \\
eGFR, mL/min/1.73 m ${ }^{2}$ & $89.88 \pm 15.59$ & $91.00 \pm 17.35$ & 0.85 \\
Uric acid, mg/dL & $5.28 \pm 0.91$ & $5.16 \pm 1.44$ & 0.79 \\
LDL, mg/dL & $125.81 \pm 31.05$ & $133.01 \pm 23.59$ & 0.55 \\
TG, mg/dL & $114.85 \pm 52.92$ & $92.30 \pm 48.32$ & 0.29 \\
\hline
\end{tabular}

Values are expressed as mean \pm standard deviation or percentage, as appropriate. AH, arterial hypertension; DBP, diastolic blood pressure; eGFR, estimated glomerular filtration rate; HR, heart rate; LDL, low-density lipoprotein; RFR, renal functional reserve; SBP, systolic blood pressure; TG, triglycerides.

Table 2. Twenty-four-hour ambulatory BP monitoring parameters in hypertensive patients with reduced or preserved RFR

\begin{tabular}{lccc}
\hline Ambulatory BP monitoring & $\mathrm{RFR}<30 \mathrm{~mL} / \mathrm{min} /$ & $\mathrm{RFR} \geq 30 \mathrm{~mL} / \mathrm{min} /$ & $p$ value \\
parameter & $1.73 \mathrm{~m}^{2}(n=21)$ & $1.73 \mathrm{~m}^{2}(n=15)$ & \\
\hline 24-h SBP, mm Hg & $134.35 \pm 12.42$ & $136.75 \pm 11.75$ & 0.60 \\
24-h DBP, mm Hg & $82.41 \pm 7.57$ & $84.58 \pm 7.83$ & 0.44 \\
24-h HR, bpm & $69.64 \pm 9.00$ & $71.18 \pm 7.69$ & 0.63 \\
\hline Daytime SBP, mm Hg & $139.14 \pm 11.54$ & $141.75 \pm 12.06$ & 0.54 \\
Daytime DBP, mm Hg & $86.00 \pm 8.01$ & $89.50 \pm 8.88$ & 0.25 \\
Daytime HR, bpm & $72.55 \pm 9.11$ & $74.45 \pm 8.47$ & 0.57 \\
\hline Nighttime SBP, mm Hg & $125.18 \pm 16.33$ & $126.17 \pm 13.93$ & 0.86 \\
Nighttime DBP, mm Hg & $75.00 \pm 9.25$ & $75.58 \pm 5.96$ & 0.85 \\
Nighttime HR, bpm & $63.64 \pm 9.21$ & $67.27 \pm 8.38$ & 0.28 \\
\hline Nondipping systolic, \% & 57.1 & 20.0 & 0.05 \\
Nondipping diastolic, \% & 52.3 & 13.3 & 0.02 \\
\hline
\end{tabular}

Values are expressed as mean \pm standard deviation or percentage, as appropriate. BP, blood pressure; DBP, diastolic blood pressure; HR, heart rate; RFR, renal functional reserve; SBP, systolic blood pressure.

higher in hypertensive patients with a RFR $<30 \mathrm{~mL} / \mathrm{min} / 1.73 \mathrm{~m}^{2}(p=0.05$ and $p=0.02$, respectively) (Fig. 1).

\section{Exercise Treadmill Stress Test Parameters}

No significant differences were found between the two groups regarding maximum SBP, $\mathrm{HR}$, and achieved estimated metabolic equivalents of task during stress test as well as for 
Fig. 1. Proportion of SBP and DBP nondippers for each RFR group. A patient can be engaged in more than one dipping pattern (both systolic and diastolic). DBP, diastolic blood pressure; RFR, renal functional reserve; SBP, systolic blood pressure.

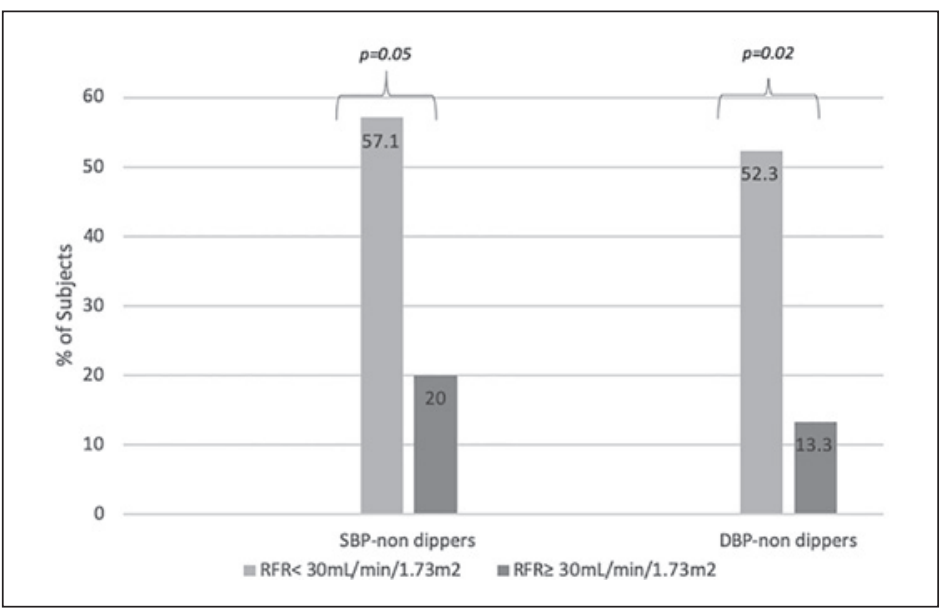

Fig. 2. Correlation of RFR and maximum HR during treadmill stress test. HR, heart rate; RFR, renal functional reserve.

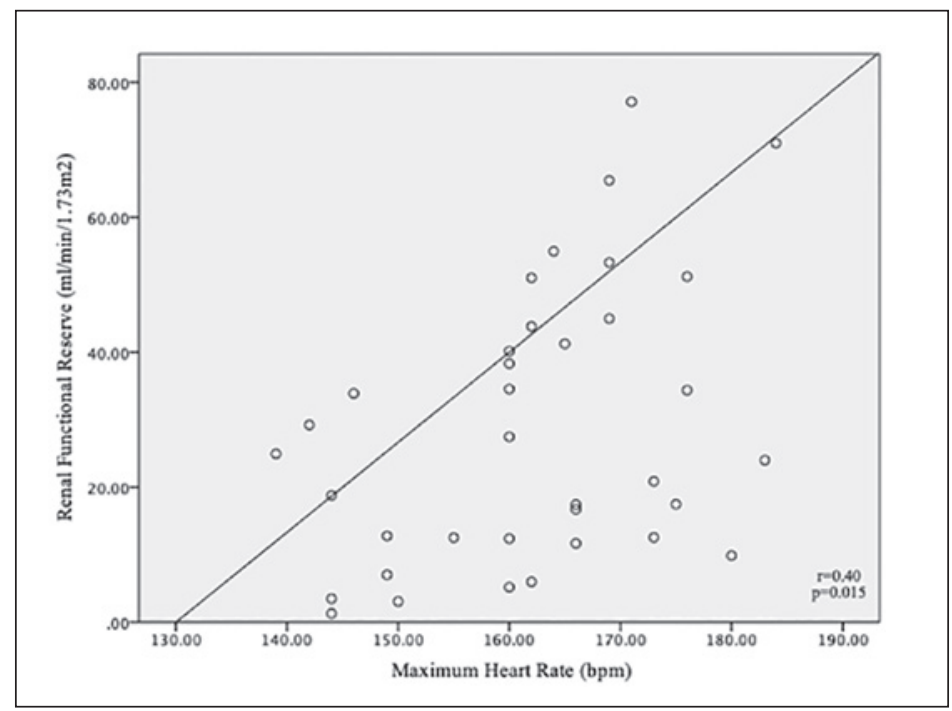

baseline BP and HR (Table 3). However, a statistically significant correlation was observed between RFR values and maximum HR during treadmill stress test. In particular, hypertensive patients with higher RFR values had higher maximum HR during treadmill test $(r=$ $0.40, p=0.015$ ) (Fig. 2).

\section{Associations of Echocardiographic Parameters with RFR in Hypertensives}

Details of echocardiographic parameters according to RFR are shown in Table 4. Measurements of left ventricular end-diastolic/systolic diameter, interventricular septum, posterior wall, left atrial diameter, and left ventricular mass index did not differ between the groups. We did not find any statistically significantly association of RFR values and any of the measured echocardiographic parameters.

\section{Discussion}

The main finding of our study is that untreated essential hypertensive patients with a normal renal function but $\mathrm{RFR}<30 \mathrm{~mL} / \mathrm{min} / 1.73 \mathrm{~m}^{2}$ tend to have a more frequent nondipping pattern of 24-h ambulatory BP and an attenuated HR response to treadmill exercise. However, 
Table 3. Treadmill parameters in the hypertensives groups

\begin{tabular}{lccc}
\hline Parameter & $\begin{array}{l}\mathrm{RFR}<30 \mathrm{~mL} / \mathrm{min} / \\
1.73 \mathrm{~m}^{2}(n=21)\end{array}$ & $\begin{array}{l}\mathrm{RFR} \geq 30 \mathrm{~mL} / \mathrm{min} / \\
1.73 \mathrm{~m}^{2}(n=15)\end{array}$ & $p$ value \\
\hline Treadmill maximum HR, bpm & $159.14 \pm 13.43$ & $166.78 \pm 10.71$ & 0.14 \\
Treadmill maximum SBP, mm Hg & $187.05 \pm 23.53$ & $191.25 \pm 21.67$ & 0.66 \\
Treadmill maximum DBP, mm Hg & $82.73 \pm 5.50$ & $82.50 \pm 4.63$ & 0.91 \\
Treadmill duration, min & $9.65 \pm 2.18$ & $9.51 \pm 1.82$ & 0.87 \\
METs & $11.21 \pm 2.38$ & $11.15 \pm 1.94$ & 0.95 \\
\hline
\end{tabular}

Values are expressed as mean \pm standard deviation. DBP, diastolic blood pressure; HR, heart rate; METs, achieved estimated metabolic equivalents of task; RFR, renal functional reserve; SBP, systolic blood pressure.

Table 4. Echocardiographic parameters in the hypertensives groups

\begin{tabular}{lccc}
\hline Parameter & RFR $<30 \mathrm{~mL} / \mathrm{min} /$ & $\mathrm{RFR} \geq 30 \mathrm{~mL} / \mathrm{min} /$ & $p$ value \\
& $1.73 \mathrm{~m}^{2}(n=21)$ & $1.73 \mathrm{~m}^{2}(n=15)$ & 0.85 \\
\hline LVEDD, mm & $47.59 \pm 4.20$ & $47.29 \pm 4.25$ & 0.53 \\
LVESD, mm & $28.81 \pm 2.99$ & $28.00 \pm 3.56$ & 0.78 \\
Interventricular septum, mm & $9.94 \pm 0.98$ & $9.81 \pm 1.67$ & 0.85 \\
Posterior wall thickness, mm & $9.48 \pm 1.05$ & $9.57 \pm 1.61$ & 0.46 \\
Left atrial diameter, mm & $37.56 \pm 3.97$ & $35.52 \pm 12.03$ & 0.62 \\
Left ventricular mass index, g/m ${ }^{2}$ & $36.97 \pm 8.86$ & $38.71 \pm 11.52$ & 0.40 \\
Transmitral flow E and A & $1.11 \pm 0.47$ & $0.97 \pm 0.41$ & 0.92 \\
Left ventricular ejection fraction, $\%$ & $59.09 \pm 1.97$ & $59.17 \pm 1.95$ & \\
\hline
\end{tabular}

Values are expressed as mean \pm standard deviation or percentage, as appropriate. LVEDD, left ventricular end-diastolic diameter; LVESD, left ventricular end-systolic diameter; RFR, renal functional reserve.

indices of hypertensive cardiac burden such as left ventricular hypertrophy are not different between those with a low or a high RFR. The association of these three clinical phenotypes (low RFR, nondipping pattern of BP, and lower HR response to exercise) may characterize a subgroup of hypertensive patients having a more pronounced impairment of systemic and renal vascular reactivity due to impaired vasodilator mechanisms. According to recent hypotheses [21, 26], these patients might be more vulnerable to develop acute as well as chronic kidney damage.

The first interesting observation of this study is that despite the fact that all participants had preserved renal function and none was diabetic, $>50 \%$ of them had a reduced RFR uncovering the presence of some asymptomatic loss of renal function. Indeed, like the heart, which increases its output under stress conditions, kidneys have the ability to increase their GFR under conditions increasing the work demand such as eating a protein-rich meal, mobilizing the RFR $[18,27]$. A reduction in RFR is classically observed in patients with diabetes and chronic kidney disease [27-30] due to renal functional as well as structural changes. As mentioned previously, a low RFR has also been documented in patients with hypertension [7-9]. In these latter, an early and partial loss of RFR may be primarily functional, due to impaired vasodilator mechanisms. Indeed, endothelial dysfunction with reduced nitric oxide release and SNS overactivity may contribute to increasing the basal tone of glomerular arterioles, which is a crucial determinant of resting GFR and hence of RFR.

Our findings suggest a link between the patients' ability to mobilize their RFR and their decrease in BP during nighttime, the nondipping pattern being more frequent in hypertensive patients with a reduced RFR. Attenuation or absence of nocturnal BP decline (nondipping) is 
frequent in hypertension and has been found in association with several concomitant conditions such as obstructive sleep apnea, endocrine diseases, chronic kidney diseases, diabetes, and heart failure [31]. In these conditions, the main mechanisms involved in the absence of nighttime BP reduction are advanced structural vascular disease and a reduced ability to excrete sodium [32] due either to a reduction in renal function or to overactivity of the SNS and the renin-angiotensin-aldosterone system [33, 34]. Thus, the nondipping pattern and blunted RFR share some common pathogenic features, mainly an overactive SNS and impaired nitric oxide release, suggesting that both phenotypes might have a similar origin, at least in some hypertensive patients. So far the clinical implication of this association is not known. However, the nondipping pattern is associated with the development of target organ damages, secondary forms of hypertension, multiple cardiovascular risk factors, and poor long-term outcomes including all-cause and cardiovascular mortality [22, 35-42]. It has also been associated with subclinical renal damage [43] and a more rapid decline in renal function in chronic kidney disease patients [22, 37-42, 44-46]. The finding that the nondipping pattern is also associated with a low RFR would further support the idea that these hypertensive patients may be more susceptible to kidney damage or progression to chronic kidney disease as suggested by Ronco et al. [47]. Yet, larger prospective studies are needed to confirm this hypothesis.

We also assessed the relationship between RFR and maximum HR during treadmill stress test. We found a significant association of RFR with peak HR (maximum HR) in essential hypertensive patients. Subjects with higher RFR appeared to have a physiological (increasing) HR response during dynamic exercise. The behavior of HR during exercise can also be considered as an indirect index of adrenergic cardiovascular ability [44]. Physiologically, as exercise workload increases, parallel increases in central influences and skeletal muscle afferent fibers increase the arterial baroreceptor reflex resetting. In turn, this augments the sympathetically-mediated increase in HR and depresses the parasympathetic HR reflex response [48-50]. Thus, as discussed with nighttime BP, the association between maximum HR response to stress and RFR may be mediated by the activity of the SNS, a high baseline vascular tone limiting both the mobilization of RFR and the ability to increase HR during exercise. Further studies examining data from treadmill stress tests in combination with ambulatory HR recordings might provide a more integrated view of the underlying regulatory mechanisms between RFR and SNS.

No differences regarding glucose levels and lipid profile were found between hypertensive patients with high and low RFR. Additionally, performing echocardiographic examination in all hypertensives enabled us to assess hypertension-mediated cardiac damage. We found no significant difference between both groups. These observations might be merely explained by the fact that patients of both groups were newly diagnosed, had a mild form of hypertension, and were neither diabetic nor obese. Therefore, our observation suggests that the reduced RFR is a very early sign of renal target organ damage. From a clinical point of view, the variability of RFR is not clearly understood, and it is hypothesized that the maintenance of the kidney's capacity to increase GFR after protein loading by nephron recruitment and increases in renal blood flow probably requires adequate vasodilator responses, intact intrinsic renal mechanisms, and consequently preserved renal functional mass [47]. While recent studies also point out a role of vasopressin in the protein-induced glomerular response [51], other complex pathogenic pathways, including the activation of diverse hormonal regulatory systems along with the SNS, might accelerate mobilization of the kidney's reserve, thus reducing RFR in the early hypertensive setting.

Today determination of albuminuria, calculation of the eGFR, and realization of a renal color Doppler ultrasound [52] are recommended by the European Society of Cardiology/ European Society of Hypertension hypertension guidelines [15] to calculate the global cardiovascular risk, to diagnose secondary forms of hypertension, and to assess target organ damage 


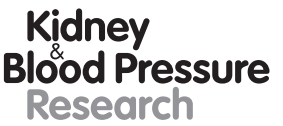

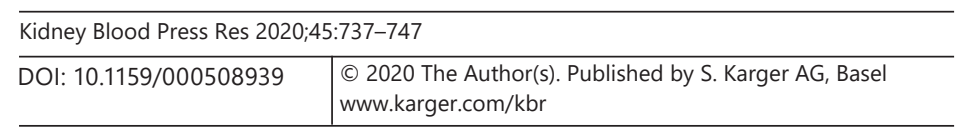

Damianaki et al.: Renal Functional Reserve, Exercise Heart Rate, and Circadian Blood Pressure

at the renal level. In theory, the addition of a RFR estimation could provide additional information to clinicians identifying a subset of patients who might perhaps benefit from more intensive BP goals and particularly from a closer follow-up of their renal function, implementing renal preventive measures such as the prescription of nephroprotective drugs, the avoidance of nephrotoxic agents, and the introduction of an effective cardiovascular protection by multifaceted interventions to risk factors.

Our study has several limitations. The first is the small size of the study group and the second the absence of any measurement of SNS activity, which appears highly relevant in this context. Another limitation is the fact that RFR was assessed using repeated $\mathrm{CrCl}$ calculations and not using inulin clearance. Indeed, UCr secretion is influenced by tubular secretion, which may differ among subjects and may be affected by the type of proteins given to test RFR. Thus, one cannot generalize our findings to younger or older patients with different vascular disease burden and different eGFR or to patients with different ethnicities. Furthermore, a delayed time response for the peak of stress GFR (after protein load) has been recently demonstrated in nonalbuminuric, nonhypertensive obese subjects compared to controls [20]. Thus, except for interpreting RFR per se, a more frequent sampling needed for assessing possible different time patterns during the mobilization of renal reserve among our subjects can also be considered a limitation of our study, as it might have given a more integrated view in the assessment of the magnitude of renal risk in certain clinical phenotypes in the hypertension setting. Indeed, in our study we used for our analysis specific time points to estimate endogenous $\mathrm{CrCl}$ before and after protein loading (online suppl. Fig. 2). On the other hand, the fact that patients were untreated is a definite strength of our study. Finally, RFR peak distribution in our sample was found to be $28.6 \mathrm{~mL} / \mathrm{min}$, following a normal distribution. This is line with the proposed literature cutoff point that characterizes an adequate renal reserve. This fact can further support our choice to analyze our results by dividing the patients in two groups: $\geq 30$ and $<30 \mathrm{~mL} / \mathrm{min} / 1.73 \mathrm{~m}^{2}$ (online suppl. Fig. 3 ).

In conclusion, RFR is related with dipping status as well as maximum exercise HR in some hypertensive patients. These findings suggest a complex multilevel interaction between the heart, vasculature, and kidneys and proposes that certain clinical phenotypes in the hypertension setting might have a greater renal risk. Whether a more systematic estimation of RFR in hypertensive patients could improve our assessment of the cardiovascular and renal prognosis of hypertensive patients remains to be determined in future studies.

\section{Statement of Ethics}

This study was approved by the Hippokration Hospital of Athens ethics committee and conducted in accordance with the 1964 Helsinki Declaration and its later amendments or comparable ethical standards. Written informed consent was obtained from the subjects involved in the study.

\section{Conflict of Interest Statement}

The authors have no conflicts of interest to declare.

\section{Funding Sources}

The authors have no funding sources to disclose. 


\section{Kidney \\ Blood Pressure Research}

\begin{tabular}{l|l}
\hline Kidney Blood Press Res 2020:45:737-747 \\
\hline DOI: 10.1159/000508939 & $\begin{array}{l}\text { @ 2020 The Author(s). Published by S. Karger AG, Basel } \\
\text { www.karger.com/kbr }\end{array}$ \\
\hline
\end{tabular}

Damianaki et al.: Renal Functional Reserve, Exercise Heart Rate, and Circadian Blood Pressure

\section{Author Contributions}

All authors contributed to conception and study design, data analysis, and drafting of the article, provided intellectual content, and approved the final version submitted.

\section{References}

1 Fattah H, Layton A, Vallon V. How Do Kidneys Adapt to a Deficit or Loss in Nephron Number? Physiology (Bethesda). 2019 May;34(3):189-97.

2 Delanaye P, Schaeffner E, Ebert N, Cavalier E, Mariat C, Krzesinski JM, et al. Normal reference values for glomerular filtration rate: what do we really know? Nephrol Dial Transplant. 2012 Jul;27(7):2664-72.

3 Sharma A, Mucino MJ, Ronco C. Renal functional reserve and renal recovery after acute kidney injury. Nephron Clin Pract. 2014;127(1-4):94-100.

4 Ronco C, Chawla LS. Glomerular and Tubular Kidney Stress Test: New Tools for a Deeper Evaluation of Kidney Function. Nephron. 2016;134(3):191-4.

5 Palsson R, Waikar SS. Renal Functional Reserve Revisited. Adv Chronic Kidney Dis. 2018 May;25(3):e1-8.

6 Muskiet MH, Smits MM, Morsink LM, Diamant M. The gut-renal axis: do incretin-based agents confer renoprotection in diabetes? Nat Rev Nephrol. 2014 Feb;10(2):88-103.

7 Zitta S, Stoschitzky K, Zweiker R, Oettl K, Reibnegger G, Holzer H, et al. Dynamic renal function testing by compartmental analysis: assessment of renal functional reserve in essential hypertension. Nephrol Dial Transplant. 2000 Aug;15(8):1162-9.

8 Grunfeld B, Perelstein E, Simsolo R, Gimenez M, Romero JC. Renal functional reserve and microalbuminuria in offspring of hypertensive parents. Hypertension. 1990 Mar;15(3):257-61.

9 Gaipov A, Solak Y, Zhampeissov N, Dzholdasbekova A, Popova N, Molnar MZ, et al. Renal functional reserve and renal hemodynamics in hypertensive patients. Ren Fail. 2016 Oct;38(9):1391-7.

10 Tsioufis C, Tatsis I, Thomopoulos C, Wilcox C, Palm F, Kordalis A, et al. Effects of hypertension, diabetes mellitus, obesity and other factors on kidney haemodynamics. Curr Vasc Pharmacol. 2014 May;12(3):537-48.

11 Grassi G, Pisano A, Bolignano D, Seravalle G, D’Arrigo G, Quarti-Trevano F, et al. Sympathetic Nerve Traffic Activation in Essential Hypertension and Its Correlates: Systematic Reviews and Meta-Analyses. Hypertension. 2018 Aug;72(2):483-91.

12 Grassi G. Assessment of sympathetic cardiovascular drive in human hypertension: achievements and perspectives. Hypertension. 2009 Oct; 54(4):690-7.

13 Grassi G, Seravalle G, Quarti-Trevano F, Dell'Oro R, Bombelli M, Cuspidi C, et al. Adrenergic, metabolic, and reflex abnormalities in reverse and extreme dipper hypertensives. Hypertension. 2008 Nov;52(5):925-31.

14 Levey AS, Bosch JP, Lewis JB, Greene T, Rogers N, Roth D; Modification of Diet in Renal Disease Study Group. A more accurate method to estimate glomerular filtration rate from serum creatinine: a new prediction equation. Ann Intern Med. 1999 Mar;130(6):461-70.

15 Williams B, Mancia G, Spiering W, Agabiti Rosei E, Azizi M, Burnier M, et al.; ESC Scientific Document Group. 2018 ESC/ESH Guidelines for the management of arterial hypertension. Eur Heart J. 2018 Sep;39(33):3021-104.

16 Sharma A, Zaragoza JJ, Villa G, Ribeiro LC, Lu R, Sartori M, et al. Optimizing a kidney stress test to evaluate renal functional reserve. Clin Nephrol. 2016 Jul;86(7):18-26.

17 Du Bois D, Du Bois EF. A formula to estimate the approximate surface area if height and weight be known. 1916. Nutrition. 1989 Sep-Oct;5(5):303-11.

18 Bosch JP, Saccaggi A, Lauer A, Ronco C, Belledonne M, Glabman S. Renal functional reserve in humans. Effect of protein intake on glomerular filtration rate. Am J Med. 1983 Dec;75(6):943-50.

19 Hostetter TH. Human renal response to meat meal. Am J Physiol. 1986 Apr;250 (4 Pt 2):F613-8.

20 Anastasio P, Viggiano D, Zacchia M, Altobelli C, Capasso G, Gaspare De Santo N. Delay in Renal Hemodynamic Response to a Meat Meal in Severe Obesity. Nephron. 2017;136(2):151-7.

21 Husain-Syed F, Ferrari F, Sharma A, Danesi TH, Bezerra P, Lopez-Giacoman S, et al. Preoperative Renal Functional Reserve Predicts Risk of Acute Kidney Injury After Cardiac Operation. Ann Thorac Surg. 2018 Apr; 105(4):1094-101.

22 Ohkubo T, Imai Y, Tsuji I, Nagai K, Watanabe N, Minami N, et al. Relation between nocturnal decline in blood pressure and mortality. The Ohasama Study. Am J Hypertens. 1997 Nov;10(11):1201-7.

23 Fletcher GF, Froelicher VF, Hartley LH, Haskell WL, Pollock ML. Exercise standards. A statement for health professionals from the American Heart Association. Circulation. 1990 Dec;82(6):2286-322.

24 Lauer MS, Levy D, Anderson KM, Plehn JF. Is there a relationship between exercise systolic blood pressure response and left ventricular mass? The Framingham Heart Study. Ann Intern Med. 1992 Feb;116(3):203-10.

25 Schiller NB, Shah PM, Crawford M, DeMaria A, Devereux R, Feigenbaum H, et al. Recommendations for quantitation of the left ventricle by two-dimensional echocardiography. American Society of Echocardiography Committee on Standards, Subcommittee on Quantitation of Two-Dimensional Echocardiograms. J Am Soc Echocardiogr. 1989 Sep-Oct;2(5):358-67. 
Damianaki et al.: Renal Functional Reserve, Exercise Heart Rate, and Circadian Blood Pressure

26 Chawla LS, Bellomo R, Bihorac A, Goldstein SL, Siew ED, Bagshaw SM, et al.; Acute Disease Quality Initiative Workgroup 16. Acute kidney disease and renal recovery: consensus report of the Acute Disease Quality Initiative (ADQI) 16 Workgroup. Nat Rev Nephrol. 2017 Apr;13(4):241-57.

27 Bosch JP, Lauer A, Glabman S. Short-term protein loading in assessment of patients with renal disease. Am J Med. 1984 Nov;77(5):873-9.

28 Bosch JP, Lew S, Glabman S, Lauer A. Renal hemodynamic changes in humans. Response to protein loading in normal and diseased kidneys. Am J Med. 1986 Nov;81(5):809-15.

29 Barai S, Gambhir S, Prasad N, Sharma RK, Ora M. Functional renal reserve capacity in different stages of chronic kidney disease. Nephrology (Carlton). 2010 Apr;15(3):350-3.

30 Shestakova MV, Mukhin NA, Dedov II, Titov VN, Warshavsky VA. Protein-loading test, urinary albumin excretion and renal morphology in diagnosis of subclinical diabetic nephropathy. J Intern Med. 1992 Mar; 231(3):213-7.

31 Kario K. Nocturnal Hypertension: New Technology and Evidence. Hypertension. 2018 Jun;71(6):997-1009.

32 Bankir L, Bochud M, Maillard M, Bovet P, Gabriel A, Burnier M. Nighttime blood pressure and nocturnal dipping are associated with daytime urinary sodium excretion in African subjects. Hypertension. 2008 Apr;51(4): 891-8.

33 Burnier M, Coltamai L, Maillard M, Bochud M. Renal sodium handling and nighttime blood pressure. Semin Nephrol. 2007 Sep;27(5):565-71.

34 Sherwood A, Steffen PR, Blumenthal JA, Kuhn C, Hinderliter AL. Nighttime blood pressure dipping: the role of the sympathetic nervous system. Am J Hypertens. 2002 Feb;15(2 Pt 1):111-8.

35 Fagard RH, Celis H, Thijs L, Staessen JA, Clement DL, De Buyzere ML, et al. Daytime and nighttime blood pressure as predictors of death and cause-specific cardiovascular events in hypertension. Hypertension. 2008 Jan;51(1):55-61.

36 Verdecchia P, Angeli F, Mazzotta G, Garofoli M, Ramundo E, Gentile G, et al. Day-night dip and early-morning surge in blood pressure in hypertension: prognostic implications. Hypertension. 2012 Jul;60(1):34-42.

37 Routledge F, McFetridge-Durdle J. Nondipping blood pressure patterns among individuals with essential hypertension: a review of the literature. Eur J Cardiovasc Nurs. 2007 Mar;6(1):9-26.

38 Cuspidi C, Sala C, Tadic M, Gherbesi E, De Giorgi A, Grassi G, et al. Clinical and prognostic significance of a reverse dipping pattern on ambulatory monitoring: an updated review. J Clin Hypertens (Greenwich). 2017 Jul;19(7):713-21.

39 Tsioufis C, Andrikou I, Thomopoulos C, Petras D, Manolis A, Stefanadis C. Comparative prognostic role of nighttime blood pressure and nondipping profile on renal outcomes. Am J Nephrol. 2011;33(3):277-88.

40 Davidson MB, Hix JK, Vidt DG, Brotman DJ. Association of impaired diurnal blood pressure variation with a subsequent decline in glomerular filtration rate. Arch Intern Med. 2006 Apr;166(8):846-52.

41 Soylu A, Yazici M, Duzenli MA, Tokac M, Ozdemir K, Gok H. Relation between abnormalities in circadian blood pressure rhythm and target organ damage in normotensives. Circ J. 2009 May; 73(5):899-904.

42 Agarwal R, Light RP. GFR, proteinuria and circadian blood pressure. Nephrol Dial Transplant. 2009 Aug;24(8): 2400-6.

43 Lurbe E, Redon J, Kesani A, Pascual JM, Tacons J, Alvarez V, et al. Increase in nocturnal blood pressure and progression to microalbuminuria in type 1 diabetes. N Engl J Med. 2002 Sep;347(11):797-805.

44 Grassi G, Quarti-Trevano F, Seravalle G, Arenare F, Volpe M, Furiani S, et al. Early sympathetic activation in the initial clinical stages of chronic renal failure. Hypertension. 2011 Apr;57(4):846-51.

45 Petras D, Koutroutsos K, Kordalis A, Tsioufis C, Stefanadis C. The role of sympathetic nervous system in the progression of chronic kidney disease in the era of catheter based sympathetic renal denervation. Curr Clin Pharmacol. 2013 Aug;8(3):197-205.

46 Tsioufis C, Dimitriadis K, Thomopoulos C, Doumas M, Papademetriou V, Stefanadis C. Renal and cardiac effects of renal sympathetic denervation and carotid baroreceptor stimulation. Curr Vasc Pharmacol. 2014 Jan;12(1): 55-62.

47 Ronco C, Bellomo R, Kellum J. Understanding renal functional reserve. Intensive Care Med. 2017 Jun; 43(6): 917-20.

48 White DW, Raven PB. Autonomic neural control of heart rate during dynamic exercise: revisited. J Physiol. 2014 Jun;592(12):2491-500.

49 Thrasher TN. Baroreceptors, baroreceptor unloading, and the long-term control of blood pressure. Am J Physiol Regul Integr Comp Physiol. 2005 Apr;288(4):R819-27.

50 Di Rienzo M, Parati G, Radaelli A, Castiglioni P. Baroreflex contribution to blood pressure and heart rate oscillations: time scales, time-variant characteristics and nonlinearities. Philos Trans A Math Phys Eng Sci. 2009 Apr;367(1892):1301-18.

51 Viggiano D, De Santo NG, Amruthraj NJ, Capolongo G, Capasso G, Anastasio P. Renal response to an oral protein load in patients with central diabetes insipidus before and after treatment with vasopressin. J Nephrol. 2019 Jun;32(3):411-5.

52 Tsioufis C, Andrikou I, Pruijm M, Ponte B, Sarafidis P, Koureas A, et al. Should renal color Doppler ultrasonography be a routine test in newly diagnosed hypertensive patient? J Hypertens. 2018 Jan;36(1):16-22. 